\title{
Involvement of BDNF Receptor TrkB in Spatial Memory Formation
}

\author{
Makoto Mizuno, ${ }^{2}$ Kiyofumi Yamada, ${ }^{1,2,3}$ Jue He, Akira Nakajima, \\ and Toshitaka Nabeshima ${ }^{3}$ \\ Department of Neuropsychopharmacology and Hospital Pharmacy, Nagoya University Graduate School of Medicine, Showa-ku, \\ Nagoya 466-8560, Japan
}

\begin{abstract}
The N-methyl-D-aspartate (NMDA) receptors are involved in long-term potentiation (LTP), and are phosphorylated by several tyrosine kinases including a Src-family tyrosine kinase Fyn. Brain-derived neurotrophic factor (BDNF) is a neurotrophin, which also enhances hippocampal synaptic transmission and efficacy by increasing NMDA receptor activity. Here, we show that Fyn is a key molecule linking the BDNF receptor TrkB with NMDA receptors, which play an important role in spatial memory formation in a radial arm maze. Spatial learning induced phosphorylation of TrkB, Fyn, and NR2B, but not NR2A, in the hippocampus. Fyn was coimmunoprecipitated with TrkB and NR2B, and this association was increased in well-trained rats compared with control animals. Continuous intracerebroventricular infusion of PP2, a tyrosine kinase inhibitor, in rats delayed memory acquisition in the radial arm maze, but PP2-treated animals reached the same level of learning as the controls. The phosphorylation of Fyn and NR2B, but not TrkB, was diminished by PP2 treatment. Our findings suggest the importance of interaction between BDNF/TrkB signaling and NMDA receptors for spatial memory in the hippocampus.
\end{abstract}

Long-term potentiation (LTP) in the hippocampus is an activity-dependent modification of synaptic strength and considered a potential cellular mechanism underlying learning and memory (Bliss and Collingridge 1993). Brain-derived neurotrophic factor (BDNF) is implicated in synaptic plasticity such as LTP (Barde et al. 1982; Leibrock et al. 1989; Patterson et al. 1992; Figurov et al. 1996). Recently, we have demonstrated that BDNF mRNA in the hippocampus increased after a radial maze training, and treatment with an antisense BDNF oligonucleotide led to impairment of not only the acquisition, but also the maintenance and/or recall of spatial memory (Mizuno et al. 2000). Although these findings imply an essential role for BDNF in spatial learning and memory, the molecular mechanisms by which BDNF regulates spatial memory processes remain to be determined (Yamada et al. 2002).

N-Methyl-D-aspartate (NMDA) receptors are heteromeric glutamate-gated ion channels in the central nervous system, which are constructed by two families of an essential subunit NR1 and other subunits NR2A-D (Hollmann and Heinemann 1994), and are involved in synaptic plasticity

\footnotetext{
${ }^{1}$ Present address: Laboratory of Experimental Therapeutics, Department of Clinical Pharmacy, Faculty of Pharmaceutical Sciences, Kanazawa University, Kanazawa 920-0934, Japan. ${ }^{2}$ These authors contributed equally to this work.

${ }^{3}$ Corresponding authors.

E-MAIL tnabeshi@med.nagoya-u.ac.jp; FAX 81-52-744-2682. E-MAIL kyamada@p.kanazawa-u.ac.jp; FAX 81-76-234-4493. Article and publication are at http://www.learnmem.org/cgi/doi/ $10.1101 / \mathrm{lm} .56003$.
}

(Collingridge 1987). Activation of NMDA receptors generates LTP, whereas inhibition and deletion of NMDA receptors impair LTP and spatial learning and memory (Morris et al. 1986; Sakimura et al. 1995; Tsien et al. 1996). NMDA receptor activity is modulated by the phosphorylation catalyzed by several protein kinases including protein kinase A, protein kinase $\mathrm{C}$, and calcium/calmodulin-dependent protein kinase II (Omkumar et al. 1996; Tingley et al. 1997; Gardoni et al. 1999).

Phosphorylation at tyrosine residues leads to an increase in NMDA current (Chen and Leonard 1996). Compelling evidence has been provided that NMDA receptors are substrates of protein tyrosine kinases. Fyn is a nonreceptor Src-family tyrosine kinase expressed abundantly in neurons and associated with NMDA receptors (Salter 1998). NR2A is tyrosine-phosphorylated when coexpressed with Fyn (Tezuka et al. 1999). Recently, it was shown that phosphorylation of NR2B at tyr-1472 mediated by Fyn is important for synaptic plasticity (Nakazawa et al. 2001). Fyn has Src homology 2 (SH2) domains, which are supposed to bind to NMDA receptors (Takagi et al. 1999). The SH2 domain is also able to bind to phosphorylated BDNF receptor TrkB in cell lysate prepared from primary rat cortical neurons stimulated with BDNF (Iwasaki et al. 1998).

Previous studies have reported that BDNF specifically promotes phosphorylation of NR1 and NR2B, which results in an enhancement of NMDA receptor activity (Suen et al. 1997; Levine et al. 1998; Lin et al. 1998). The blockade of the NR2B subunit prevents the BDNF-induced enhance-

LEARNING \& MEMORY 10:108-115 @ 2003 by Cold Spring Harbor Laboratory Press ISSN1072-0502/03 \$5.00

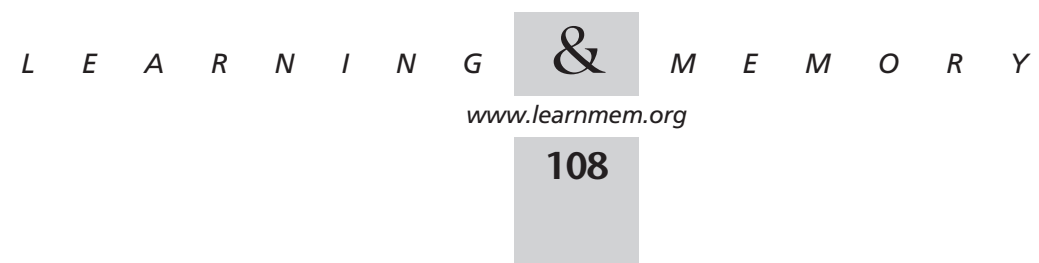


ment of glutamatergic neurotransmission (Crozier et al. 1999). Thus, phosphorylaton of NR2B is particularly crucial to the effect of BDNF and this post-translational modification is associated with LTP (Rostas et al. 1996).

In this study, we have investigated the interaction between BDNF signaling and NMDA receptors in spatial learning and memory. Here, we show that Fyn plays an important role in this interaction for spatial memory.

\section{RESULTS}

\section{Spatial Learning-Induced Phosphorylation of Fyn and NR2B}

We have demonstrated previously that the hippocampus is important for spatial memory formation in the radial arm
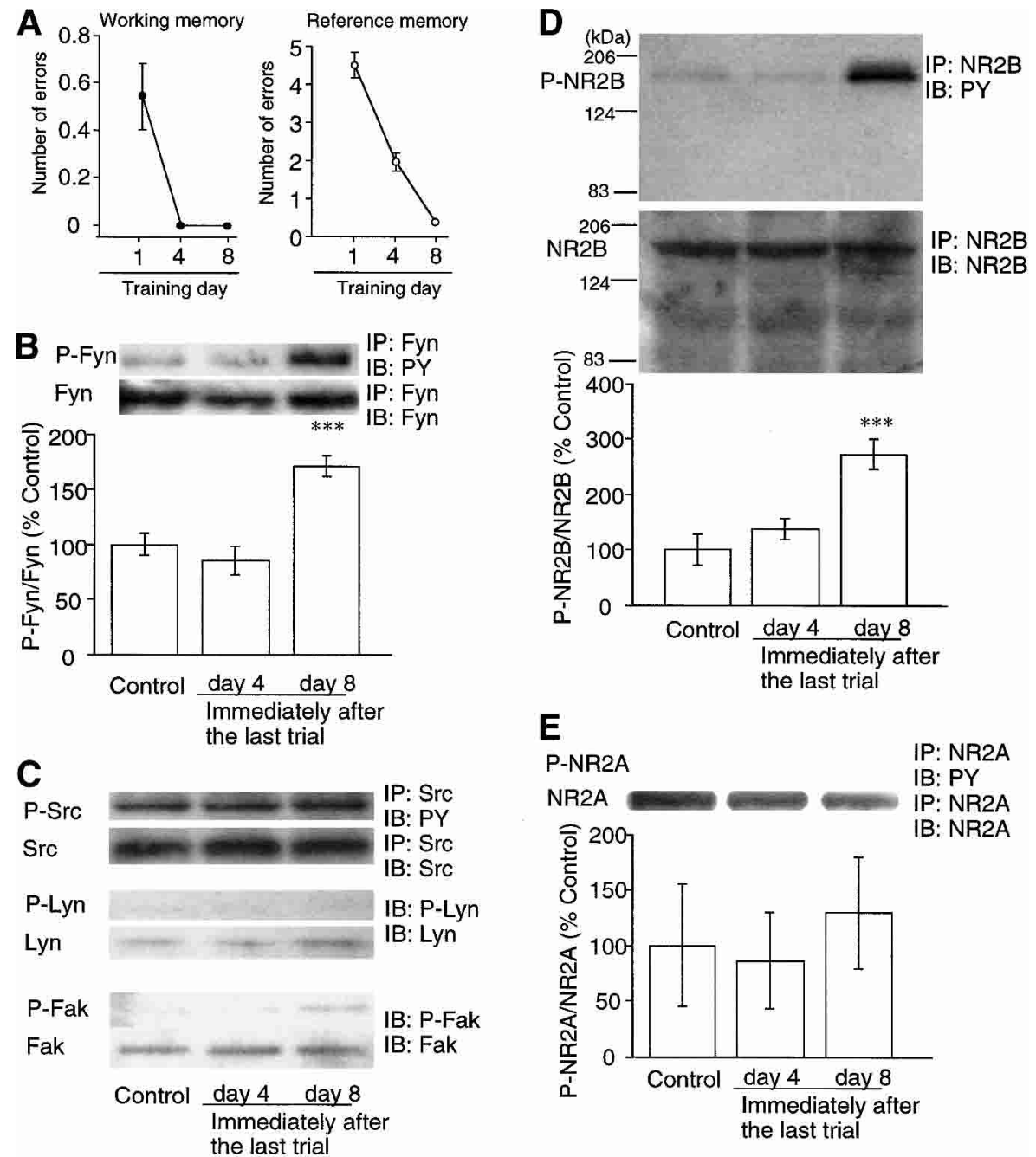

Figure 1 Spatial memory formation and protein phosphorylation. Spatial working and reference memory formation in rats $(n=8)(A)$. Learning-associated tyrosine phosphorylation of Fyn $(B)$, Src, Lyn, and Fak $(C)$, NR2B $(D)$, and NR2A $(E)$ in the hippocampus. (IP) Immunoprecipitation; (IB) immunoblotting. Data are expressed as a percentage of control. Each value represents the mean \pm S.E. $(n=5) .(* * *) P<0.001$ vs. control. maze (Zou et al. 1998; He et al. 2002; Mizuno et al. 2002), and that BDNF mRNA expression and TrkB phosphorylation are increased in the hippocampus of rats that acquired spatial memory (Mizuno et al. 2000, 2003). Because Fyn is known to associate with TrkB when stimulated with BDNF, we examined whether the radial arm maze training causes activation of Fyn in the hippocampus. Thus, rats were first trained for the reference and working memory task, three trials per day for eight successive days. Figure 1A shows the changes of working and reference errors in performance of rats in the radial arm maze after daily training (three trials per day). One-way ANOVA revealed that daily training significantly decreased the number of both working $[\mathrm{F}(2,21)=14.975, P<0.0001]$ and reference memory errors $[\mathrm{F}(2,21)=71.364, P<0.0001]$.

The level of phosphorylated Fyn in the hippocampus of trained rats did not change on day 4 , but increased on day $8(171.5 \pm 9.2 \%$ control), compared with that in the nontrained control group $[\mathrm{F}(2,12)=30.995, P<0.001]$. No changes in total Fyn protein levels were observed among the three groups (Fig. 1B). We also examined phosphorylation of other nonreceptor tyrosine kinases (Src, Lyn, and Fak). According to quantification, the levels of these phosphorylated kinases in the hippocampus of trained rats did not change either on day 4 or day 8 , compared with those in the control group. We show only representative pictures of gels (Fig. 1C). Thus, there is some specificity for the activation of Fyn in the hippocampus of trained rats. We also analyzed whether spatial memory formation is associated with phosphorylation of NMDA receptor subunits, NR2A and NR2B. To test this, NR2A and NR2B subunits were immunoprecipitated with respective specific antibodies and then blotted with anti-phospho tyrosine antibodies (PY). NR2B phosphorylation in the hippocampus was markedly increased on day 8 , but not day 4 , in the trained rats compared with control rats $[\mathrm{F}(2,12)=22.524$, $P<0.001$ ] (Fig. 1D), whereas NR2A phosphorylation did not change

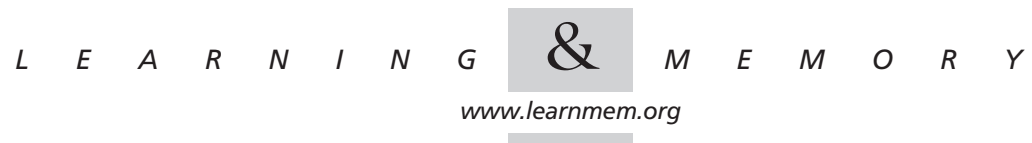


$[\mathrm{F}(2,12)=0.3232, P=0.7299]$ (Fig. 1E). These results suggest that the phosphorylation of Fyn and NR2B after the maze training is related to the formation of spatial memory. We further examined whether an increase in the phosphorylation of TrkB and NR2B after maze training is associated with an activation of Fyn. To this end, total Fyn was immunoprecipitated with specific antibody, and the samples were blotted with anti-TrkB, anti-NR2A, or antiNR2B antibodies. Western blotting revealed a significant increase in the association of Fyn with TrkB on day 4 $[\mathrm{F}(2,12)=126.21, P<0.01]$ and day $8[\mathrm{~F}(2,12)=126.21$, $P<0.001]$ (Fig. 2A), and with NR2B on day 8 $[\mathrm{F}(2,12)=40.242, P<0.001]$ (Fig. 2B). There were no learning-dependent changes in the association between Fyn and NR2A (Fig. 2C) $[\mathrm{F}(2,12)=0.5174, P=0.6088]$. These
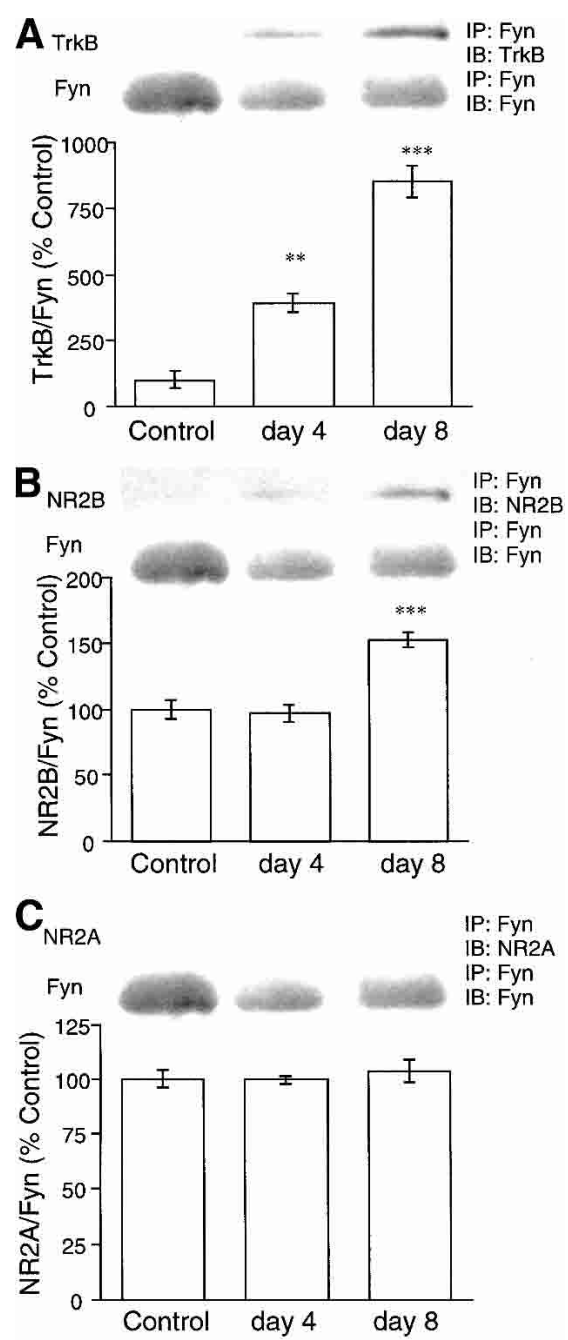

Figure 2 Learning-associated increase in association of Fyn with $\operatorname{TrkB}(A), \mathrm{NR} 2 \mathrm{~B}(B)$, and NR2A $(C)$ in the hippocampus. (IP) Immunoprecipitation; (IB) immunoblotting. Data are expressed as a percentage of control. Each value represents the mean \pm S.E. $(n=5)$. (**) $P<0.01 ;(* *) P<0.001$ vs. control. results suggest an enhanced association of TrkB and NR2B with Fyn. Our previous study indicated that levels of phosphorylated TrkB were extremely low in the nontrained control animals, but significantly increased $>300 \%$ on day 8 , immediately after the training (Mizuno et al. 2003). Collectively, these results suggest that spatial learning in the radial arm maze induced phosphorylation of TrkB, Fyn, and NR2B, and the association of these molecules in the hippocampus.

\section{Tyrosine Kinase Inhibitor Impaired Spatial Memory}

To investigate the causal relation between the activation of Fyn and formation of spatial memory, rats that received a continuous intracerebroventricular infusion of PP2, an inhibitor of Src-family protein kinases (Hanke et al. 1996) were subjected to the spatial learning test. The infusion of PP2 significantly impaired spatial learning. A two-way ANOVA with repeated measures of the data revealed significant effects of group $[\mathrm{F}(1,10)=5.526, P=0.0406]$, trial $[\mathrm{F}(6,60)=37.113, P<0.0001]$, and group by trial interaction $[\mathrm{F}(6,60)=4.021, P=0.0019]$ on reference memory. Post-hoc analysis with Scheffe's test indicated that the group by trial interaction was significant $(P<0.05$, Fig. 3A). There were also significant effects of group $[\mathrm{F}(1,10)=10.542, P=0.0088]$ and trial $[\mathrm{F}(6,60)=5.668$, $P=0.0001]$, but not group by trial interaction $[\mathrm{F}(6,60)=2.127, P=0.0632]$, on working memory (Fig. 3B). There was no apparent difference in locomotor speed $[\mathrm{F}(1,10)=3.348, P=0.0972]$ (Fig. 3C), body weight (Fig. $3 \mathrm{D}$ ), and food consumption (Fig. 3E) between the two groups of animals. Thus, it is unlikely that the PP2-induced impairment of maze performance is due to alterations of locomotor function, motivation for food, or toxicity. To confirm the effect of PP2 on the phosphorylation of Fyn and signal transduction, rats were killed immediately after the behavioral test, immediately after the last training trial on day 7 , and levels of phosphorylated Fyn, NR2B, and TrkB were determined. Phosphorylated Fyn $(P<0.001$, Fig. 4A) and NR2B $(P<0.05$, Fig. 4B) levels were significantly lower in the hippocampus of the PP2-treated rats $(n=4$ or 5$)$ than vehicle-treated rats $(n=4$ or 5$)$. In contrast, there was no difference in phosphorylated TrkB levels between the two groups of rats $(n=4)$ (Fig. 4C). Collectively, these results suggest that activation of Fyn and the association of Fyn to NR2B is important for spatial memory.

\section{DISCUSSION}

We demonstrated in the present study that phosphorylation of Fyn and NR2B, not Src, Lyn, Fak, and NR2A, in the hippocampus is associated with spatial memory formation in the radial arm maze. Levels of phosphorylated Fyn and NR2B were the same as the control on day 4 , but increased on day 8 of training when spatial memory was firmly

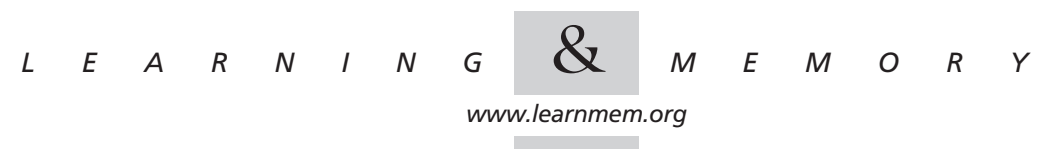



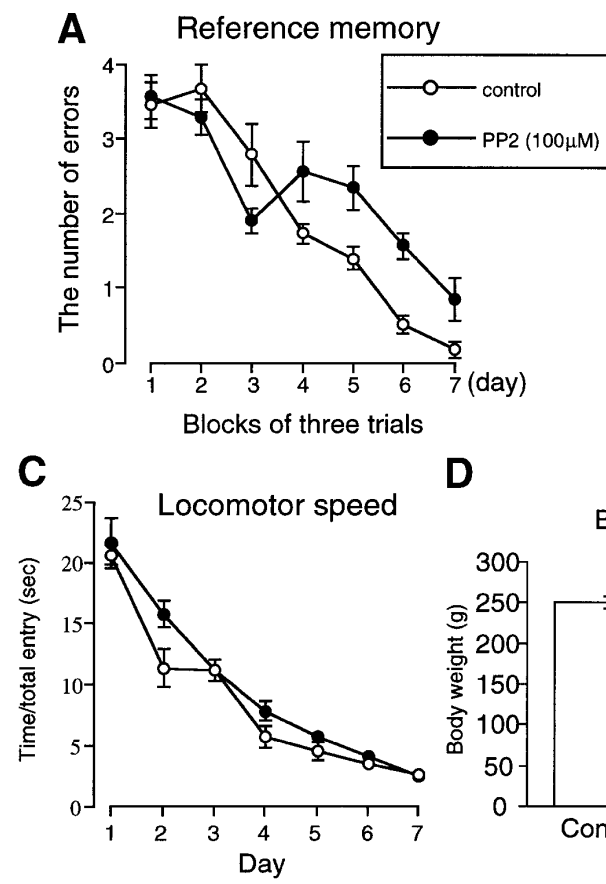

D
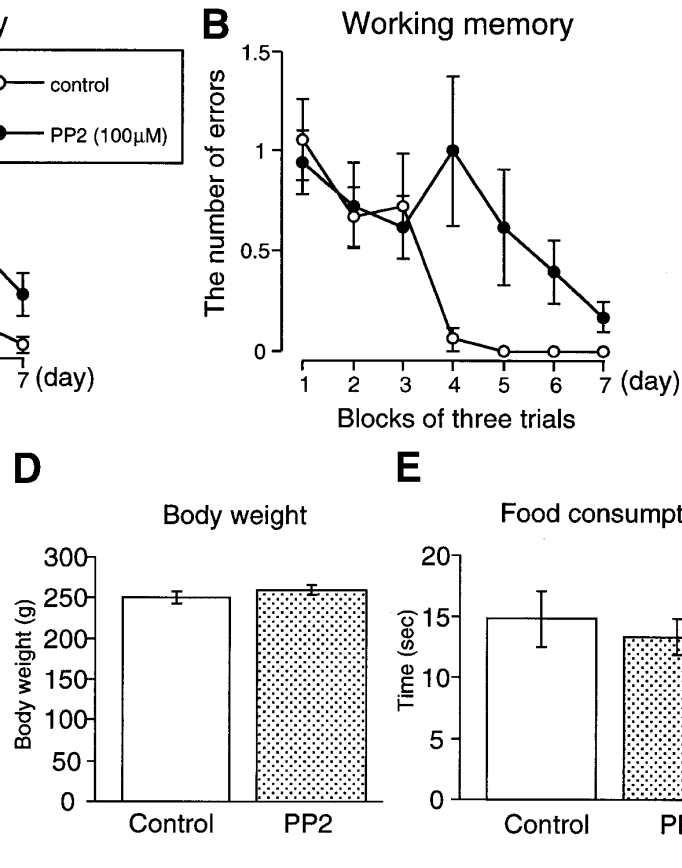

E

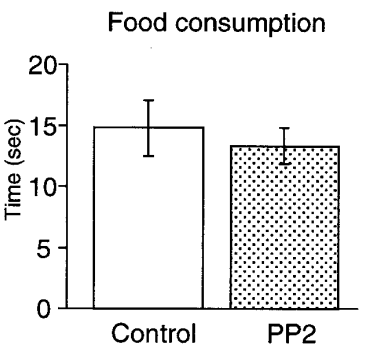

Figure 3 Behavioral effect of continuous intracerebroventricular infusion of PP2 on spatial learning. Changes in the number of reference memory errors $(A)$, working memory errors $(B)$, and Locomotor speed $(C)$. Body weight $(D)$ and food consumption $(E)$ were measured on day 7 . Each value represents the mean \pm S.E. $(n=5)$.

formed. It should be determined whether the observed changes in NR2B phosphorylation are directly related to learning and memory per se, especially reference memory formation. Some concerns have been raised regarding the contribution of stress to NR2B activation during the learning of taste (Kim et al. 1996; Rosenblum et al. 1997). To reduce the contribution of stress, animals were habituated extensively to the test environment and apparatus before starting the actual learning trials. Because the increase in phosphorylated Fyn and NR2B was observed on day 8, not day 4 , it is unlikely that the effect of stress has a major role in the activation of Fyn and NR2B.

We have demonstrated previously that phosphorylation of cAMP response element-binding protein (CREB) and cAMP-dependent protein kinase A (PKA) is increased on day 4 in the hippocampus of rats trained for spatial learning and memory under the same experimental conditions, suggesting that PKA/CREB-signaling pathway plays an important role in spatial memory formation (Mizuno et al. 2002). In contrast, we observed in the present study, when memory formation is quite significant (on day 4), that phosphorylation of TrkB, Fyn, and NR2B was absent, but when the memory appears to be stabilized (day 8), the measures were present. A position of rat in space is encoded by the coordinated activity of individual hippocampal pyramidal cells called place cells, and the activity of place cells is thought to be the basis of a map of the environment that the animal uses for solving spatial problems (O'Keefe and Speakman 1987). Therefore, a plausible argument on this issue is that once spatial memory is firmly formed, place cell, etc., are more active in the hippocampus, and it is the repetitive activation of this type of hippocampal representation that activates such molecular pathways. Alternatively, the activation of TrkB/ Fyn/NR2B signaling may be associated with the processes of memory consolidation and retention. In fact, continuous intracerebroventricular infusion of antisense BDNF oligonucleotide in rats, which had previously acquired spatial memory by an extensive training, caused spatial memory deficit, suggesting a role of $\mathrm{BDNF}$ in the retention and/or recall of spatial memory (Mizuno et al. 2000),

Previous studies have demonstrated that Fyn and NMDA receptors are involved in anxiety-associated learning. For instance, Fyn (Grant et al. 1992), NR1 (Tsien et al. 1996), and NR2A (Sakimura et al. 1995) knockout mice are selectively impaired in a hippocampus-dependent spatial memory in the Morris water maze. Because NR2B knockout mice died shortly after birth (Kutsuwada et al. 1996), the relation of NR2B to spatial memory was determined by using transgenic mice that overexpress NR2B (Tang et al. 1999). Spatial learning and memory were superior in the transgenic mice. Accordingly, our results support these previous findings and suggest that activation of the Fyn and NR2B pathway is also associated with spatial learning in the food-motivated radial arm maze task. It remains to be determined why only NR2B, but not NR2A, was phosphorylated in the hippocampus of trained rats, as previous studies have demonstrated that Fyn could phosphorylate and modulate NR1/NR2A receptors (Tezuka et al. 1999).

BDNF stimulates TrkB receptors, resulting in its association with Fyn, and the activated Fyn binds to NR2A and NR2B via SH2 domains (Iwasaki et al. 1998). To test the hypothesis that Fyn is a crucial mediator of the signal transduction from TrkB to NR2B, we examined the effects of pharmacological blockade of tyrosine kinase activity with PP2 on spatial memory. PP2 impaired maze learning in rats without affecting motivation and locomotor function, but PP2-treated animals reached the same level of learning as the controls at the end of the behavioral test. These results suggest that PP2 treatment delayed, but did not inhibit,

$$
\begin{array}{lllllllllllllll} 
& E & A & R & N & I & N & G & \& & M & E & M & O & R & Y \\
\text { www.learnmem.org } & & & &
\end{array}
$$



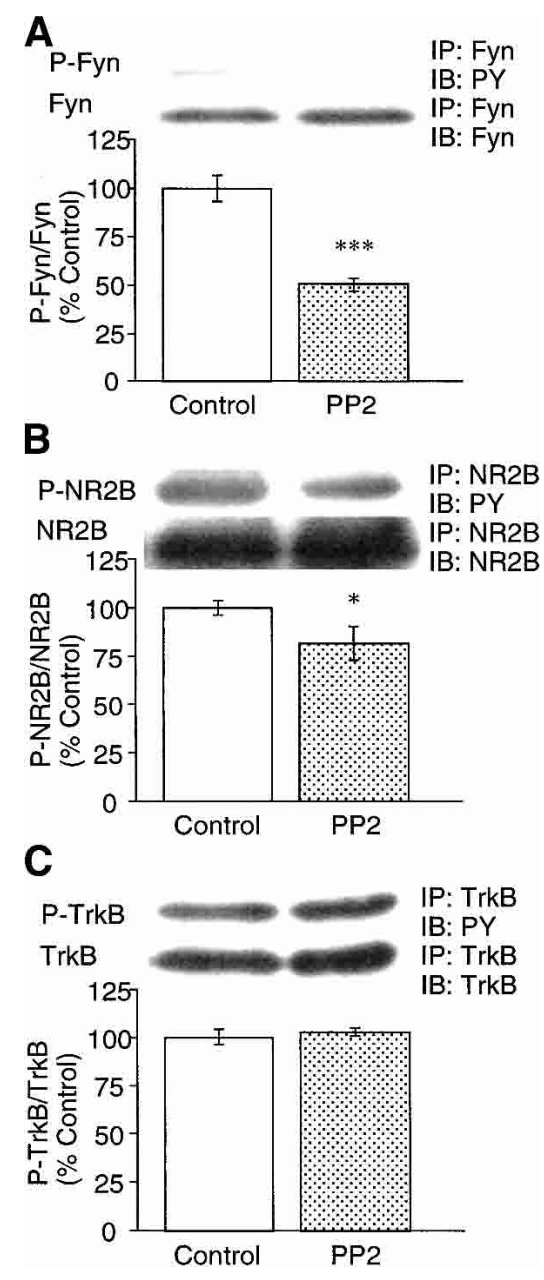

Figure 4 Effects of continuous intracerebroventricular infusion of PP2 on learning-associated tyrosine phosphorylation of Fyn $(A)$, NR2B $(B)$, and TrkB (C) in the hippocampus. (IP) Immunoprecipitation, (IB) immunoblotting. Data are expressed as a percentage of control. Each value represents the mean \pm S.E. $\left.(n=4-5) \quad{ }^{*}\right)$ $P<0.05 ;\left(^{* * *}\right) P<0.001$ vs. control.

spatial memory formation. Because PP2 effectively inhibited both reference and working memory formation in a similar fashion, we consider that activation of Fyn is important in the processes of both spatial reference and working memory acquisition.

Fyn is one of the nonreceptor type tyrosine kinases of the Src-family and PP2 is a nonselective inhibitor of Srcfamily tyrosine kinases (Hanke et al. 1996). Continuous intracerebroventricular infusion of PP2 in rats delayed memory acquisition in the radial arm maze. Thus, one might consider that the inhibitory effect of PP2 on spatial memory in the radial arm maze is not due to the inhibition of Fyn, but other tyrosine kinases are involved. However, among nonreceptor tyrosine kinases examined in the present study, only Fyn kinase was activated in the hippocampus of trained rats, whereas phosphorylation of other tyrosine ki- nases including Src, Lyn, and Fak did not change. Furthermore, we confirmed that the levels of phosphorylated Fyn in the hippocampus of the PP2-infused rats decreased. PP2 inhibited the phosphorylation of NR2B, although it had no effect on that of TrkB. Therefore, it is suggested that the $\mathrm{BDNF} / \mathrm{TrkB} / \mathrm{Fyn} / \mathrm{NR} 2 \mathrm{~B}$-signaling pathway is attributable to spatial memory formation in the radial arm maze.

In contrast to the inhibitory effect of PP2 on spatial memory processes, it has been shown that Fyn-deficient mice are normal in radial arm maze learning (Miyakawa et al. 1996), whereas they show deficits in water maze learning (Grant et al. 1992). The discrepancy between the present findings and Miyakawa's results may be due to the compensation of the Fyn deficiency during the development and growth in the mutant mice. Thus, to prove our hypothesis, development of novel Fyn-deficient mice is necessary to show the hippocampus-specific deletion during the training period.

Although a delay of reference memory formation was induced by treatment with PP2, the inhibitory effect was quite small and the number of errors may reach the same level of learning as the controls in the end of training when compared with that found in rats infused with the antisense BDNF oligonucleotide (Mizuno et al. 2000). We speculate that protein kinases other than Fyn may be involved in the phosphorylation of NR2B. In fact, compared with the marked decrease in phosphorylated Fyn induced by PP2, the decrease in phosphorylated NR2B was minimal, suggesting an involvement of other tyrosine kinases in learninginduced NR2B phosphorylation. NR1, NR2A, and NR2B can be phosphorylated, for example, by a mitogen-activated protein kinase in hippocampal tissue (Bi et al. 2000). Alternatively, it is plausible that other signaling molecules in addition to Fyn are involved in BDNF/TrkB-dependent memory formation. Actually, activation of the TrkB/PI3-K/ Akt-signaling pathway by BDNF in the hippocampus is necessary for spatial learning (Mizuno et al. 2003).

It has been suggested that synaptogenesis is involved in LTP and memory formation (Constantine-Paton and Cline 1998). TrkB receptor ligands including BDNF and neurotrophin- 4 promote inhibitory synaptogenesis in Purkinje cells (Seil and Drake-Baumann 2000). Recently, it was demonstrated that hippocampal mossy fiber synaptogenesis induced by water maze training is related to long-term spatial memory and the synaptogenesis is inhibited by administration of the NMDA antagonist MK-801 before the maze training (Ramirez-Amaya et al. 2001). It is of interest to examine whether spatial memory formation in the radial arm maze is also associated with synaptogenesis and to test the involvement of BDNF in learning-induced modification of synaptic structures.

In conclusion, our findings indicate the importance of the interaction between BDNF/TrkB signaling and NMDA receptors for spatial memory formation. Fyn may play a key

$$
\begin{array}{lllllllllllllll} 
& E & A & R & N & I & N & G & \mathcal{Z} & M & E & M & O & R & Y \\
\text { www.learnmem.org } & & &
\end{array}
$$


role in this interaction by linking TrkB with NR2B. Other signaling pathways, including various kinases and receptors, could also be involved in establishing spatial memory.

\section{METHODS}

\section{Radial Arm Maze Task}

Male Wistar rats (7-wk old) weighing $230 \pm 10 \mathrm{~g}$ at the beginning of experiments were used. Following habituation, their weights were maintained at about $80 \%$ of these under free-feeding conditions by restricting their daily food consumption. The radial arm maze consisted of eight arms, numbered 1 to $8(48 \times 12 \mathrm{~cm})$, extending radially from a central area $(32 \mathrm{~cm}$ in diameter), with a $5-\mathrm{cm}$ edge around the apparatus. The training procedure was essentially the same as described previously (Mizuno et al. 2000). Before the actual training began, the animals were shaped for $4 \mathrm{~d}$ to run to the end of the arms and consume the bait. The bait was initially available throughout the maze, but gradually was restricted to the food cup. Following this shaping period, each animal was placed individually in the center of the maze and subjected to a reference and working memory task for 3 trials per $8 \mathrm{~d}$, in which the same four arms (Nos. 1, 2, 4, and 7) were baited for each daily training trial. The other four arms (Nos. 3, 5, 6, and 8) were never baited. The training trial continued until all four baits in the food cups had been consumed or until $5 \mathrm{~min}$ had elapsed. Measures were made of the number of reference memory errors (entering an arm that was not baited) and working memory errors (entering an arm containing food but previously entered). The other group of animals was prepared as nontrained control rats. They were kept on a restricted diet, the same as the experimental groups, placed on the radial arm maze every day without maze training, and given four food pellets. The trained rats were killed immediately after the last maze training either on day 4 or day 8 . The control group of animals was killed on day 8 . We have demonstrated previously that extramaze, but not intramaze cues play a crucial role in the radial arm maze performance under our experimental condition (Zou et al. 1998).

\section{Intracerebroventricular Infusion of Tyrosine Kinase Inhibitor}

Tyrosine kinase inhibitor, 4-amino-5-(4-chlorophenyl)-7-(t-butyl) pyrazolo [3,4-d] pyrimidine (PP2), was purchased from Calbiochem. Rats were anesthetized with pentobarbital $(50 \mathrm{mg} / \mathrm{kg}$, i.p.) and placed in a stereotaxic apparatus. An infusion cannula connected to a miniosmotic pump (Alza) placed subcutaneously in the neck of the rat, was implanted into the right ventricle (A, $-0.3, \mathrm{~L}$, $1.2, \mathrm{~V}, 4.5$,) according to the rat brain atlas (Paxinos and Watson 1982). PP2 (100 $\mu \mathrm{M})$ was infused continuously into the cerebral ventricle for $11 \mathrm{~d}$ (flow rate, $0.5 \mu \mathrm{L} / \mathrm{h}$ ). Four days after the surgery, the rats were subjected to the reference and working memory test ( 3 trials per day for $7 \mathrm{~d}$ ). Locomotor speed, body weight, and food consumption were measured to see whether motor function and/ or motivation were affected by the treatment. Locomotor speed was calculated by total time/number of total entries in the daily training. Food consumption was measured as follows: Rats were placed individually in a home cage, and then 10 baits, which were the same as those used in the radial arm maze test, were provided. The time taken to consume all 10 baits was recorded.

\section{Immunoprecipitation and Western Blotting}

The rats were killed by decapitation and the hippocampi were dissected on ice for the immunoprecipitation and Western blotting.
The hippocampus from each rat was lysed at $4^{\circ} \mathrm{C}$ in a buffer composed of $50 \mathrm{mM}$ Tris- $\mathrm{HCl}, 150 \mathrm{mM} \mathrm{NaCl}, 10 \mathrm{mM} \mathrm{NaF}, 10 \mathrm{mM}$ EDTA, $1 \% \mathrm{NP}-40,1 \mathrm{mM}$ sodium orthovanadate, $10 \mathrm{mM}$ sodium diphosphate decahydrate, $0.5 \mathrm{mM}$ DTT, $0.2 \mathrm{mM}$ PMSF, $4 \mu \mathrm{g} / \mathrm{mL}$ pepstatin, $4 \mu \mathrm{g} / \mathrm{mL}$ aprotinin, and $4 \mu \mathrm{g} / \mathrm{mL}$ leupeptin ( $\mathrm{pH} 7.4$ ). The lysate then was centrifuged at $10,000 \mathrm{~g}$ for $10 \mathrm{~min}$. The protein concentration of the supernatant was determined with a Protein Assay Rapid kit (Wako). For phosphorylation analysis of Lyn and Fak (pyk2), $50 \mu \mathrm{g}$ of protein was boiled in a sample buffer [0.25\% bromophenol blue/ $0.25 \%$ xylene cyanol/30\% glycerol/20\% 2×TBE (90 mM Tris/64.6 $\mathrm{mM}$ boric acid/2.5 mM EDTA at $\mathrm{pH} 8.4$ )] and applied onto a $7.5 \%$ polyacrylamide gel and subsequently transferred to PVDF (MILLIPORE), and blocked with Detector Block Kit (KPL). Membranes were incubated with anti-phospho-Lyn (1:1000 dilution; Santa Cruz Biotechnology) or anti-phospho-Fak antibodies (1:1000 dilution; Santa Cruz Biotechnology), and washed with TBST (10 $\mathrm{mM}$ Tris- $\mathrm{HCl}$ at $\mathrm{pH} 7.4$, and $150 \mathrm{mM} \mathrm{NaCl}, 0.1 \%$ Tween 20) three times for $10 \mathrm{~min}$ each, and probed with horseradish peroxidaseconjugated secondary antibodies for $2 \mathrm{~h}$ at room temperature. The immune complexes were detected by ECL (Amersham Pharmacia) and exposed to X-ray film. The band intensities of the film were analyzed by densitometry. To calculate the phosphorylated form versus total protein, the same membranes were stripped with a stripping buffer (100 mM 2-mercaptoethanol, 2\% SDS, $62.5 \mathrm{mM}$ Tris- $\mathrm{HCl}$ at $\mathrm{pH} 6.7)$ at $50^{\circ} \mathrm{C}$ for $10 \mathrm{~min}$, incubated with anti-Lyn (1:1000 dilution; Santa Cruz Biotechnology) or anti-Fak antibodies (1:1000 dilution; Santa Cruz Biotechnology), and detected as described above.

For phosphorylation analysis of TrkB, Fyn, Src, NR2A, and NR2B, Protein A-Sepharose (Amersham Pharmacia) was incubated with either monoclonal anti-TrkB, anti-Fyn, anti-Src, anti-NR2A, or anti-NR2B antibodies (all from Santa Cruz Biotechnology) for $6 \mathrm{~h}$, and then with each lysate ( $0.5 \mathrm{mg}$ of protein) overnight. The immunoprecipitate was boiled in Laemmli sample buffer, separated on a $7.5 \%$ polyacrylamide gel and subsequently transferred to a PVDF membrane. The membranes were blocked and probed with either anti-phosphotyrosine (anti-PY) (1:1000 dilution: Upstate Biotechnology), anti-TrkB (1:1000 dilution), anti-NR2A (1:1000 dilution), or anti-NR2B (1:1000 dilution) antibodies, and detected as described above. To confirm equal loading of each protein, membranes were stripped with the stripping buffer, incubated with either anti-TrkB (1:1000 dilution), anti-Fyn (1:1000 dilution), antiSrc (1:1000 dilution), anti-NR2A (1:1000 dilution), or anti-NR2B (1:1000 dilution) antibodies, and detected as described above. For the quantification of protein phosphorylation and protein-protein interaction, the mean values in the control group were converted to $100 \%$ as a definition, and then individual data, including control groups, were recalculated as percent of the mean values. All of the data in Western blotting were expressed as percent of control.

All experiments were performed in accordance with the Guidelines for Animal Experiments of the Nagoya University School of Medicine, the Guiding Principles for the Care and Use of Laboratory Animals approved by the Japanese Pharmacological Society and the United States National Institutes of Health Guide for the Care and Use of Laboratory Animals.

\section{Statistical Analysis}

Results were expressed as means \pm S.E. The significance of differences was determined by a one-way ANOVA, followed by Bonferroni's test for multi-group comparisons. Student's t test was used for two-group comparisons. An ANOVA with repeated measures, followed by Scheffe's test, was conducted for analyzing data of the

\section{$\begin{array}{lllllllllllllllllll}L & E & A & R & N & I & N & G & \& & M & E & M & O & R & Y\end{array}$}


radial arm maze. A $P$ value $<0.05$ was regarded as statistically significant

\section{ACKNOWLEDGMENTS}

This study was supported in part by Grant-in-Aid for Science Research (Nos. 14370031 and 14658249) and by Special Coordination Funds for Promoting Science and Technology, Target-Oriented Brain Science Research Program from the Ministry of Education, Culture, Sports, Science and Technology of Japan.

The publication costs of this article were defrayed in part by payment of page charges. This article must therefore be hereby marked "advertisement" in accordance with 18 USC section 1734 solely to indicate this fact.

\section{REFERENCES}

Barde, Y.A., Edgar, D., and Thoenen, H. 1982. Purification of a new neurotrophic factor from mammalian brain. EMBO J. 1: 549-553.

Bi, R., Broutman, G., Foy, M.R., Thompson, R.F., and Baudry, M. 2000. The tyrosine kinase and mitogen-activated protein kinase pathways mediate multiple effects of estrogen in hippocampus. Proc. Natl. Acad. Sci. 97: 3602-3607

Bliss, T. and Collingridge, G. 1993. A synaptic model of memorylong-term potentiation in the hippocampus. Nature 361: 31-39.

Chen, C. and Leonard, J.P. 1996. Protein tyrosine kinase-mediated potentiation of currents from cloned NMDA receptors. J. Neurochem. 67: 194-200.

Collingridge, G. 1987. Synaptic plasticity. The role of NMDA receptors in learning and memory. Nature 330: 604-605

Constantine-Paton, M. and Cline, H.T. 1998. LTP and activity-dependent synaptogenesis: The more alike they are, the more different they become. Curr. Opin. Neurobiol. 8: 139-148.

Crozier, R.A., Black, I.B., and Plummer, M.R. 1999. Blockade of NR2B-containing NMDA receptors prevents BDNF enhancement of glutamatergic transmission in hippocampal neurons. Learn Mem. 6: 257-266.

Figurov, A., Pozzo-Miller, L.D., Olafsson, P., Wang, T., and Lu, B. 1996 Regulation of synaptic responses to high-frequency stimulation and LTP by neurotrophins in the hippocampus. Nature 381: 706-709.

Gardoni, F., Schrama, L.H., van Dalen, J.J., Gispen, W.H., Cattabeni, F., and Di Luca, M. 1999. $\alpha$ CaMKII binding to the C-terminal tail of NMDA receptor subunit NR2A and its modulation by autophosphorylation. FEBS Lett. 456: 394-398.

Grant, S.G., O'Dell, T.J., Karl, K.A., Stein, P.L., Soriano, P., and Kandel, E.R. 1992. Impaired long-term potentiation, spatial learning, and hippocampal development in fyn mutant mice. Science 258: 1903-1910.

Hanke, J.H., Gardner, J.P., Dow, R.L., Changelian, P.S., Brissette, W.H. Weringer, E.J., Pollok, B.A., and Connelly, P.A. 1996. Discovery of a novel, potent, and Src family-selective tyrosine kinase inhibitor. Study of Lck- and FynT-dependent T cell activation. J. Biol. Chem. 271: 695-701.

He, J., Yamada, K., and Nabeshima, T. 2002. A role of Fos expression in the CA3 region of the hippocampus in spatial memory formation in rats. Neuropsychopharmacology 26: 259-268.

Hollmann, M. and Heinemann, S. 1994. Cloned glutamate receptors. Annu Rev. Neurosci. 17: 31-108.

Iwasaki, Y., Gay, B., Wada, K., and Koizumi, S. 1998. Association of the Src family tyrosine kinase Fyn with TrkB. J. Neurochem. 71: 106-111.

Kim, J.J., Foy, M.R., and Thompson, R.F. 1996. Behavioral stress modifies hippocampal plasticity through N-methyl-D-aspartate receptor activation. Proc. Natl. Acad. Sci. 93: 4750-4753.

Kutsuwada, T., Sakimura, K., Manabe, T., Takayama, C., Katakura, N., Kushiya, E., Natsume, R., Watanabe, M., Inoue, Y., Yagi, T., et al 1996. Impairment of suckling response, trigeminal neuronal pattern formation, and hippocampal LTD in NMDA receptor $\varepsilon 2$ subunit mutant mice. Neuron 16: 333-344.
Leibrock, J., Lottspeich, F., Hohn, A., Hofer, M., Hengerer, B., Masiakowski, P., Thoenen, H., and Barde, Y.A. 1989. Molecular cloning and expression of brain-derived neurotrophic factor. Nature 341: 149-152.

Levine, E.S., Crozier, R.A., Black, I.B., and Plummer, M.R. 1998. Brain-derived neurotrophic factor modulates hippocampal synaptic transmission by increasing $\mathrm{N}$-methyl-D-aspartic acid receptor activity. Proc. Natl. Acad. Sci. 95: 10235-10239.

Lin, S.Y., Wu, K., Levine, E.S., Mount, H.T., Suen, P.C., and Black, I.B 1998. BDNF acutely increases tyrosine phosphorylation of the NMDA receptor subunit $2 \mathrm{~B}$ in cortical and hippocampal postsynaptic densities. Mol. Brain Res. 55: 20-27.

Miyakawa, T., Yagi, T., Kagiyama, A., and Niki, H. 1996. Radial maze performance, open-field and elevated plus-maze behaviors in Fyn-kinase deficient mice: Further evidence for increased fearfulness. Mol. Brain Res. 37: 145-150.

Mizuno, M., Yamada, K., Olariu, A., Nawa, H., and Nabeshima, T. 2000. Involvement of brain-derived neurotrophic factor in spatial memory formation and maintenance in a radial arm maze test in rats. $J$. Neurosci. 20: 7116-7121

Mizuno, M., Yamada, K., Maekawa, N., Saito, K., Seishima, M., and Nabeshima, T. 2002a. CREB phosphorylation as a molecular marker of memory processing in the hippocampus for spatial learning. Behav. Brain Res. 133: 135-141.

Mizuno, M., Yamada, K., Takei, N., Tran, M.H., He, J., Nakajima, A., Nawa, H., and Nabeshima, T. 2003. Protein synthesis regulated by BDNF signal pathway is important in reconsolidation of spatial memory. Mol. Psychiatry (in press)

Morris, R.G., Anderson, E., Lynch, G.S., and Baudry, M. 1986. Selective impairment of learning and blockade of long-term potentiation by an $\mathrm{N}$-methyl-D-aspartate receptor antagonist, AP5. Nature 319: 774-776.

Nakazawa, T., Komai, S., Tezuka, T., Hisatsune, C., Umemori, H., Semba, K., Mishina, M., Manabe, T., and Yamamoto, T. 2001. Characterization of Fyn-mediated tyrosine phosphorylation sites on GluR $\varepsilon 2$ (NR2B) subunit of the N-methyl-D-aspartate receptor. J. Biol. Chem. 276: 693-699.

O'Keefe, J. and Speakman, A. 1987. Single unit activity in the rat hippocampus during a spatial memory task. Exp. Brain Res. 68: 1-27.

Omkumar, R.V., Kiely, M.J., Rosenstein, A.J., Min, K.T., and Kennedy, M.B. 1996. Identification of a phosphorylation site for calcium/ calmodulindependent protein kinase II in the NR2B subunit of the N-methyl-D-aspartate receptor. J. Biol. Chem. 271: 31670-31678.

Patterson, S.L., Grover, L.M., Schwartzkroin, P.A., and Bothwell, M. 1992. Neurotrophin expression in rat hippocampal slices: A stimulus paradigm inducing LTP in CA1 evokes increases in BDNF and NT-3 mRNAs. Neuron 9: 1081-1088.

Paxinos, G. and Watson, C. 1982. The rat brain in stereotaxic coordinates Academic Press, New York, NY.

Ramirez-Amaya, V., Balderas, I., Sandoval, J., Escobar, M.L., and Bermudez-Rattoni, F. 2001. Spatial long-term memory is related to mossy fiber synaptogenesis. J. Neurosci. 21: 7340-7348.

Rosenblum, K., Berman, D.E., Hazvi, S., Lamprecht, R., and Dudai, Y. 1997. NMDA receptor and the tyrosine phosphorylation of its $2 \mathrm{~B}$ subunit in taste learning in the rat insular cortex. J. Neurosci. 17: 5129-5135

Rostas, J.A., Brent, V.A., Voss, K., Errington, M.L., Bliss, T.V., and Gurd, J.W. 1996. Enhanced tyrosine phosphorylation of the 2B subunit of the N-methyl-D-aspartate receptor in long-term potentiation. Proc. Natl. Acad. Sci. 93: 10452-10456.

Sakimura, K., Kutsuwada, T., Ito, I., Manabe, T., Takayama, C., Kushiya, E. Yagi, T., Aizawa, S., Inoue, Y., Sugiyama, H., et al. 1995. Reduced hippocampal LTP and spatial learning in mice lacking NMDA receptor $\varepsilon 1$ subunit. Nature 373: 151-155.

Salter, M.W. 1998. N-methyl-D-aspartate (NMDA) receptors, and synaptic plasticity. Biochem. Pharmacol. 56: 789-798.

Seil, F.J. and Drake-Baumann, R. 2000. TrkB receptor ligands promote activity-dependent inhibitory synaptogenesis. J. Neurosci. 20: $5367-5373$

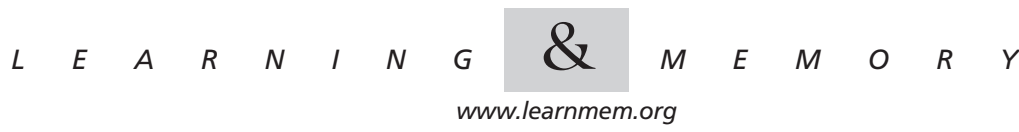


Suen, P.C., Wu, K., Levine, E.S., Mount, H.T., Xu, J.L., Lin, S.Y., and Black, I.B. 1997. Brain-derived neurotrophic factor rapidly enhances phosphorylation of the postsynaptic N-methyl-D-aspartate receptor subunit 1. Proc. Natl. Acad. Sci. 94: 8191-8195.

Takagi, N., Cheung, H.H., Bissoon, N., Teves, L., Wallace, M.C., and Gurd, J.W. 1999. The effect of transient global ischemia on the interaction of Src and Fyn with the N-methyl-D-aspartate receptor and postsynaptic densities: Possible involvement of Src homology 2 domains. J. Cereb. Blood Flow Metab. 19: 880-888.

Tang, Y.P., Shimizu, E., Dube, G.R., Rampon, C., Kerchner, G.A., Zhuo, M., Liu, G., and Tsien, J.Z. 1999. Genetic enhancement of learning and memory in mice. Nature 401: 63-69.

Tezuka, T., Umemori, H., Akiyama, T., Nakanishi, S., and Yamamoto, T. 1999. PSD-95 promotes Fyn-mediated tyrosine phosphorylation of the N-methyl-D-aspartate receptor subunit NR2A. Proc. Natl. Acad. Sci. 96: 435-440.

Tingley, W.G., Ehlers, M.D., Kameyama, K., Doherty, C., Ptak, J.B., Riley,
C.T., and Huganir, R.L. 1997. Characterization of protein kinase A and protein kinase $\mathrm{C}$ phosphorylation of the $\mathrm{N}$-methyl-D-aspartate receptor NR1 subunit using phosphorylation site-specific antibodies. J. Biol. Chem. 272: 5157-5166.

Tsien, J.Z., Huerta, P.T., and Tonegawa, S. 1996. The essential role of hippocampal CA1 NMDA receptor-dependent synaptic plasticity in spatial memory. Cell 87: 1327-1338.

Yamada, K., Mizuno, M., and Nabeshima, T. 2002. Role for brain-derived neurotrophic factor in learning and memory. Life Sci. 70: 735-744.

Zou, L.-B., Yamada, K., Tanaka, T., Kameyama, T., and Nabeshima, T. 1998. Nitric oxide synthase inhibitors impair reference memory formation in a radial arm maze task in rats. Neuropharmacology 37: 323-330.

Received October 1, 2002; accepted in revised form February 3, 2003.

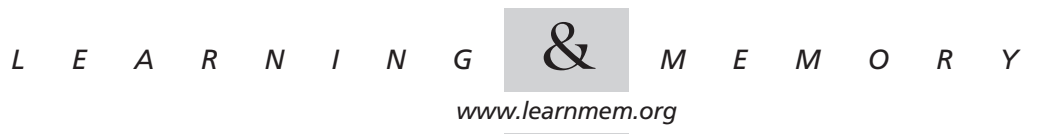




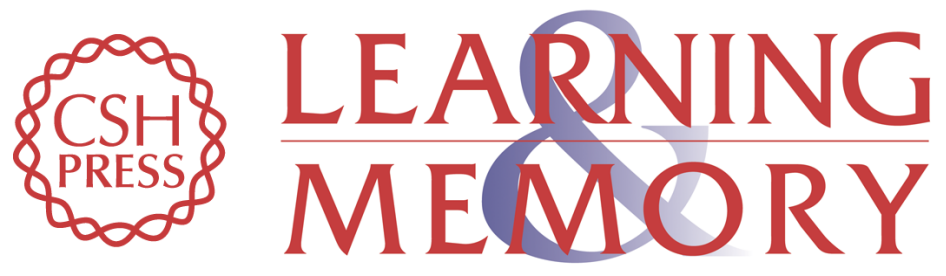

\section{Involvement of BDNF Receptor TrkB in Spatial Memory Formation}

Makoto Mizuno, Kiyofumi Yamada, Jue He, et al.

Learn. Mem. 2003, 10:

Access the most recent version at doi:10.1101//m.56003

References This article cites 41 articles, 16 of which can be accessed free at: http://learnmem.cshlp.org/content/10/2/108.full.html\#ref-list-1

License

Email Alerting Receive free email alerts when new articles cite this article - sign up in the box at the Service top right corner of the article or click here. 